\title{
ACID BASE BALANCE AND ANAESTHESIA
}

\author{
BY \\ B. G. B. LUCAS AND E. H. MILNE \\ From the Surgical Unit, University College Hospital Medical School, London
}

(RECEIVED FOR PUBLICATION JUNE 9, 1955)

The acidosis that occurs during clinical anaesthesia was formerly thought to be metabolic in origin because of inefficient carbohydrate breakdown in the unconscious state (Van Slyke, Austin, and Cullen, 1922). More recent authors (Taylor and Roos, 1950 ; Beecher and Murphy, 1950) have suggested that the acidosis is respiratory, due to defective ventilation, and the present work was undertaken to ascertain whether this was so and whether it was preventable. Acid base changes have been studied on 166 anaesthetized patients undergoing surgery (see Table) and the results assessed in relation to ventilation and posture.

TABLE

ANALYSIS OF SURGICAL CASES STUDIED

\begin{tabular}{|c|c|c|c|c|}
\hline \multicolumn{3}{|c|}{ Type of Operation } & \multirow[b]{2}{*}{$\begin{array}{r}42 \\
7 \\
8 \\
4 \\
6 \\
16\end{array}$} & \multirow[b]{2}{*}{83} \\
\hline $\begin{array}{l}\text { Abdominal operations } \\
\text { Gastrectomy } \\
\text { Cholecystectomy } \\
\text { Resection of colon } \\
\text { Abdomino-perineal } \\
\text { Renal operations } \\
\text { Hernia repair }\end{array}$ & $\begin{array}{ll}\text { Is: } & \\
\ldots & \ldots \\
\ldots & \ldots \\
\text { l resection } \\
\ldots & \ldots \\
\ldots & \ldots\end{array}$ & $\begin{array}{l}\ldots \\
\ldots \\
\text { rectum } \\
\ldots \\
\ldots\end{array}$ & & \\
\hline $\begin{array}{l}\text { Thoracic operations: } \\
\text { Lobectomy } \\
\text { Pneumonectomy } \\
\text { Oesophagectomy } \\
\text { Thoracotomy only } \\
\text { Thoracoplasty }\end{array}$ & $\begin{array}{l}\cdots \\
\cdots \\
\cdots\end{array}$ & $\begin{array}{l}\cdots \\
\cdots \\
\cdots \\
\cdots \\
\cdots\end{array}$ & $\begin{array}{r}37 \\
12 \\
4 \\
8 \\
3\end{array}$ & 64 \\
\hline \multirow[t]{2}{*}{$\begin{array}{l}\text { Limb operations: } \\
\text { (Varicose veins) }\end{array}$} & . & $\cdots$ & 19 & 19 \\
\hline & Total & . & 166 & 166 \\
\hline
\end{tabular}

During the investigation some of the clinical disturbances of respiration and circulation which frequently accompany anaesthesia were found to be directly related to these changes.

\section{Method}

The degree of acidosis was estimated from the tension of carbon dioxide in the blood. Direct measurement was found to be impracticable and so the tension was calculated from the total carbon dioxide content and $p \mathrm{H}$ of the blood, using the HendersonHasselbalch equation (Peters and Van Slyke, 1932). The blood carbon dioxide content was measured by means of Scholander and Roughton's (1943) micro- volumetric technique which was selected because of the small quantity of blood required $(0.2 \mathrm{ml}$.) and the ease and speed with which the analysis could be carried out in the operating theatre. This method gave readings of 1 to $2 \mathrm{vol} \%$ lower than the standard Van Slyke technique, an insignificant difference for the purpose of comparative estimation. Capillary blood samples were obtained from the nail bed, the limb being kept warm and elevated and free from constriction so that the blood gas levels approximated to those in arterial samples. The $p \mathrm{H}$ was measured electrometrically, venous blood being withdrawn under mercury into a special syringe which contained the electrodes in a sidechamber (Fig. 1). The samples were obtained from the superior vena cava by means of a polythene catheter inserted via an arm vein. Arterial blood was not used because of the undesirability of having indwelling arterial needles in a clinical experiment. The $p \mathrm{H}$ of the venous blood was compared periodically with that of arterial samples and was found to be 0.02 lower. This figure is in agreement with the findings of Best and Taylor (1955), and was therefore added to the venous readings. Observations were made 24 hours pre-operatively, immediately before anaesthesia, at 20-minute intervals during operation, and at one, four, and 12 hours postoperatively. Blood pressure readings were taken at the same time as the blood samples.

The premedication was papaveritum ("omnopon ") and scopolamine for all patients, although a small number received a barbiturate in addition. The anaesthetic agent was thiopentone. with tubocurarine or

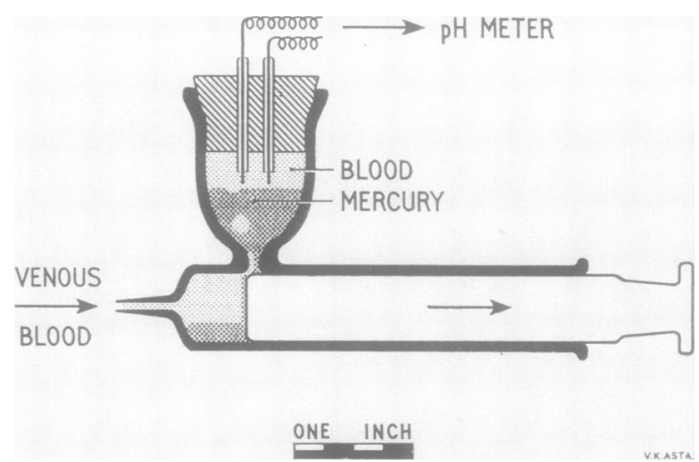

FIG. 1.-Syringe for sampling blood with simultaneous estimation of $p \mathrm{H}$. 
gallamine ("flaxedil ") for relaxation. Occasionally pethidine was substituted for thiopentone to maintain anaesthesia. On a few occasions procaine, or its amide, was administered intravenously during operation in an attempt to produce bronchodilatation. All patients were intubated with a large-bore cuffed endotracheal tube and ventilation was carried out with the carbon dioxide absorption technique, using a Waters canister. Some were allowed to breathe spontaneously and the tidal volume estimated by collecting the expired gases into a small spirometer periodically. The majority, however, were ventilated artificially by manual compression of the rebreathing bag. In order to measure the amount of ventilation under the conditions of controlled respiration a special valve (Fig. 2) was fitted to the anaesthetic circuit, arranged in such

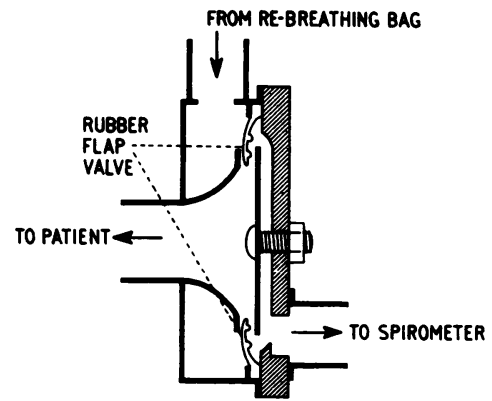

FIG. 2. Schematic diagram of valve used to facilitate collection of expir eld gases during controlled respiration technique.

a way that the expired gases could be collected in a spirometer. The rate of artificial ventilation was standardized, whenever possible, at 20 times per minute and the volume at either $500 \mathrm{ml}$. (minute volume 10 litres) or $700 \mathrm{ml}$. (minute volume 14 litres); the latter volume represented "vigorous" overventilation. It is interesting to note that the measured amount of ventilation obtained by manual compression of the rebreathing bag was considerably below that which was estimated by the operator. The rebreathing bag had to be emptied almost completely to obtain $700 \mathrm{ml}$. in one "squeeze," a technique which is seldom employed in ordinary controlled respiration.

\section{RESUlts}

SuPINE Position.-Sixty-five patients undergoing abdominal surgery were operated on in the supine position. Forty-five were allowed to breathe spontaneously during operation and the tidal volume ranged between 75 and $350 \mathrm{ml}$. with an average minute volume of 4 litres. Within 15 minutes of induction all had developed an acidosis which was not related to the peritoneum being opened. The $p \mathrm{H}$ varied from 7.3 to 6.9 with a $\mathrm{CO}_{2}$ tension of 70 to $95 \mathrm{~mm}$. Respirations were controlled in the remaining 20 patients with the "standard" ventilation of $500 \mathrm{ml}$. at 20 per minute (minute volume 10 litres). In 12 of these the $p \mathrm{H}$ and $\mathrm{pCO}_{2}$ were unaltered. In the other eight a mild acidosis ( $p H$ 7.36-7.28) developed during the course of operation but was eliminated by "vigorous" overventilation.

Lateral Position with Table "Broken."The effect of this position was studied in 89 patients, 64 of whom were undergoing thoracic operations, six renal, and 19 minor operations on the extremities. All were ventilated with the "standard" method. A rise in $\mathrm{CO}_{2}$ tension of 13 to $45 \mathrm{~mm}$. and fall in $p \mathrm{H}$ of 0.1 to 0.41 occurred in every patient on posturing, with a further divergence on breaking the table. In the thoracic cases the acidosis persisted, or increased, until the operation was completed and the chest closed. In the remainder the acidosis could be reduced by "vigorous" overventilation, but normal $\mathrm{pCO}_{2}$ and $p \mathrm{H}$ values were not regained until the patient was again placed in the supine position.

Trendelenburg Position.-Twelve patients were operated on tilted head down and eight undergoing minor limb operations were deliberately tipped for a short time. The 12 abdominal cases were allowed to breathe spontaneously, and all developed an acidosis, the severity depending upon the degree of tilt. The maximum tilt of $45^{\circ}$ resulted in a $\mathrm{pCO}_{2}$ of $92 \mathrm{~mm}$. The eight cases of varicose veins were ventilated with the "standard " method, and all developed a slight acidosis which could be reduced by increasing the ventilation but could never be restored to normal until the table was returned to the horizontal.

\section{Discussion}

This investigation reveals that the changes in blood $p \mathrm{H}$ which occur during anaesthesia can be respiratory in origin. In the conscious state the minute to minute control of $p \mathrm{H}$ is brought about by the sensitivity of the respiratory centre causing variations in ventilation, but in the anaesthetized subject this sensitivity is lost. Before the advent of modern anaesthesia respiration was the main guide to depth, so drugs which were primarily respiratory depressants were avoided for obvious reasons. To-day, with the common use of barbiturates and relaxants, profound respiratory depression is unavoidable. The normal minute volume of the unanaesthetized subject at rest is approximately 6 litres (Comroe, Forster, Dubois, Briscoe, and Carlsen, 1955). In the series reported here some of the patients who breathed spontaneously under anaesthesia had a minute volume as low as $1 \frac{1}{2}$ litres, but in spite of this low figure no clinical change in blood oxygenation was noticed, probably because they were respiring a $50 \%$ oxygen-nitrogen mixture. The elimination of 
carbon dioxide, however, was grossly inadequate and on many occasions a severe acidosis occurred. The minimum $p \mathrm{H}$ observed (6.9) would, under any other medical circumstances, be regarded as dangerous and must be harmful even if present only for a short time. By using a positive pressure controlled artificial respiration technique a normal acid base balance could be maintained, but a larger minute volume (14 litres) than was at first envisaged was found to be necessary, being more than double that of the conscious resting state. Positive pressure respiration, therefore, is relatively inefficient. Possibly the carbon dioxide absorption technique used was unsatisfactory, but this is unlikely because the flow-rate of gases was 6 litres a minute, the excess escaping from an expiratory valve, and the soda lime canister was changed every hour. The contents of the rebreathing bag were not analysed for carbon dioxide, but even with complete rebreathing the standard Waters canister is known to be efficient for one hour (Robson and Pask, 1954). Alternatively, all the patients might have been too lightly anaesthetized so that they had a bronchoconstriction and hence inadequate ventilation. To ascertain whether this was a factor, 11 of the patients undergoing thoracic operations were given intravenous procaine, or its amide, in order to obtain a bronchodilatation. All of them showed a less marked acidosis (Fig. 3), but the minute volume ventilation still had to be increased above that of the resting conscious state.

The most likely explanation is that the haemodynamics of the pulmonary circulation are altered

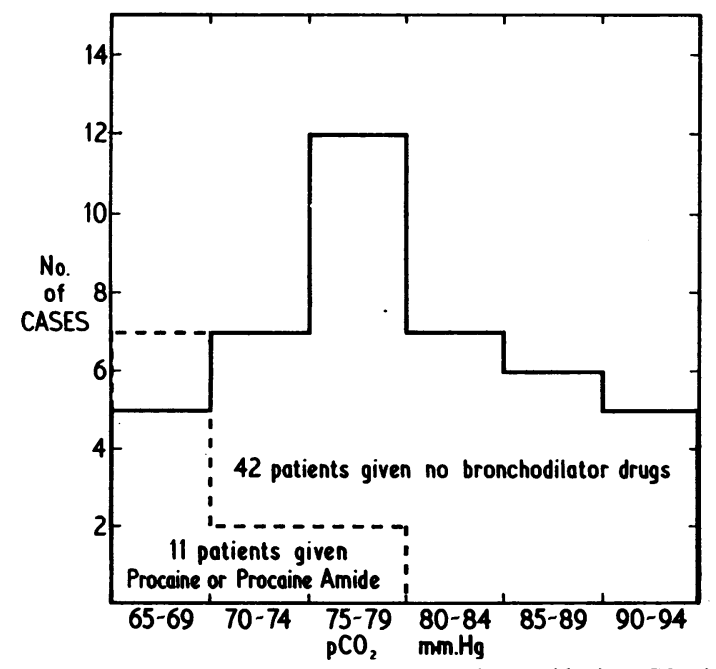

FIG. 3.-The effect of procaine or procaine amide in $\mathrm{pCO}_{2}$ in thoracic operations. by the positive pressure used in artificial ventilation. Under conditions of natural spontaneous respiration during the inspiratory phase there is a negative pressure in the alveoli which aids pulmonary capillary blood flow, but with positive pressure artificial ventilation the rise in alveolar pressure during the inspiratory phase will tend to occlude the capillaries, so reducing the flow and hindering gaseous exchange (Cournand, Motley, Werko, and Richards, 1948). Some workers (Ankeney, Hubay, Hackett, and Hingson, 1954) have suggested that the cycle of positive pressure respiration should include a deliberate pause between expiration and inspiration in order to allow the pulmonary circulation to return to normal. This presupposes that most of the gaseous interchange in the lungs takes place during the passive phase. Our investigation does not support this view; varying the relative lengths of the different phases of the respiratory cycle made no difference to carbon dioxide elimination. Moreover, if a pause were made beween each breath, the rate could not be increased sufficiently to maintain effective ventilation. No direct measurement of the impedance of pulmonary blood flow was made, but the hypothesis is supported by the fact that carbon dioxide elimination became increasingly difficult as the inspiratory positive pressure was increased. The average pressure necessary for ventilation in the supine position was $10 \mathrm{~cm}$. water, but, as might be expected, this was greatly increased in the Trendelenburg position and the high pressure partly accounted for the inability to maintain a normal acid base balance under any circumstances. In this position also blood "pools" in the lungs and reduces effective ventilation still further. The failure to obtain efficient ventilation in the lateral position is less understandable. The patient's weight on one side of the thorax might prevent the dependent side from being ventilated, but there is no apparent reason why this should apply to movement of the dependent diaphragm. N However, poor expansion of the underlying lung probably was the cause of the defective ventilation because, if the table was "broken" and the hemithorax compressed still further, the acidosis increased.

Although this paper is primarily concerned with ventilatory and acid base studies during surgery, it became obvious during the investigation that a respiratory acidosis had an effect on the patients' general condition. Those who had an acidosis during operations of short duration had a rise in blood pressure which fell abruptly immediately 
q Aps:70.

Qesophagectomy:

Effect of ventilation.

ANESTHETIC: Pentothal 0.5gm., Curore 25mg., Pethidine 180 mg.

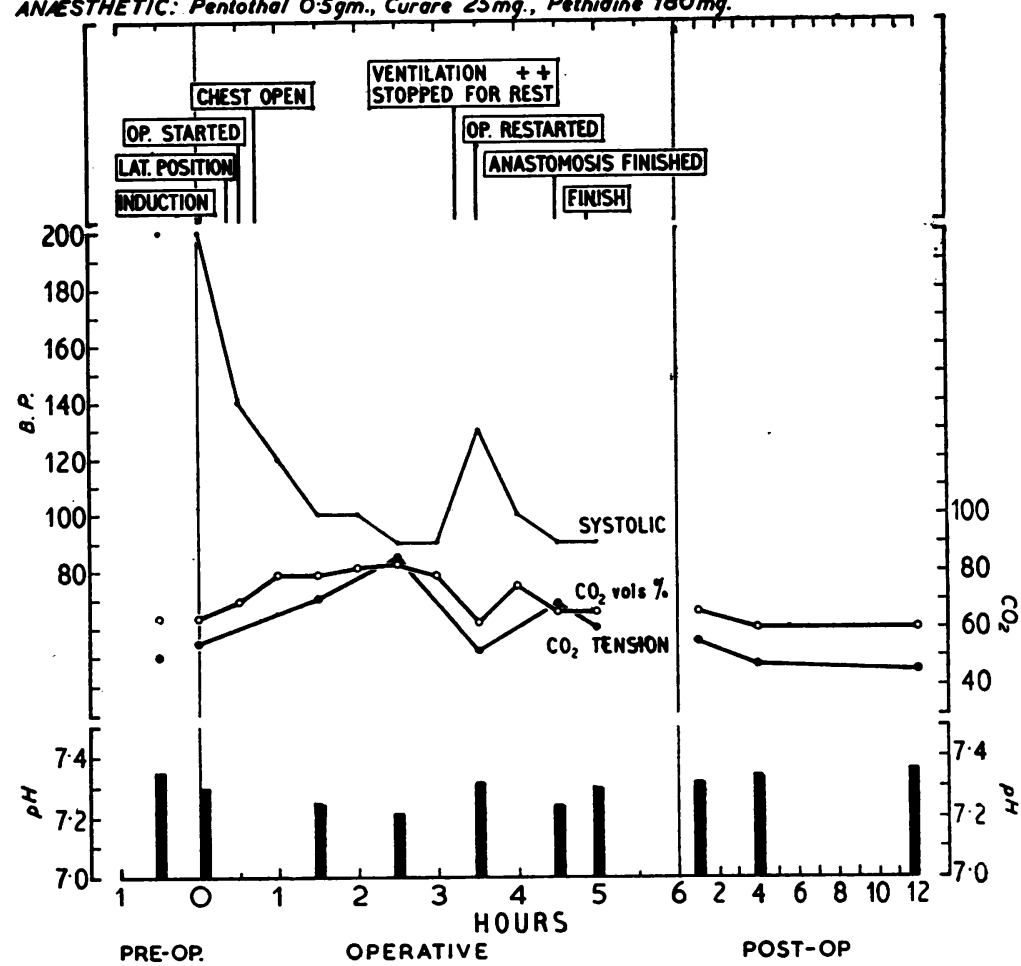

FIG. 4.-Operative chart of patient undergoing oesophagectomy (from Lucas, B. G. B., and Milne, E. H. (1953), Proc. roy. Soc. Med., 46, 365).

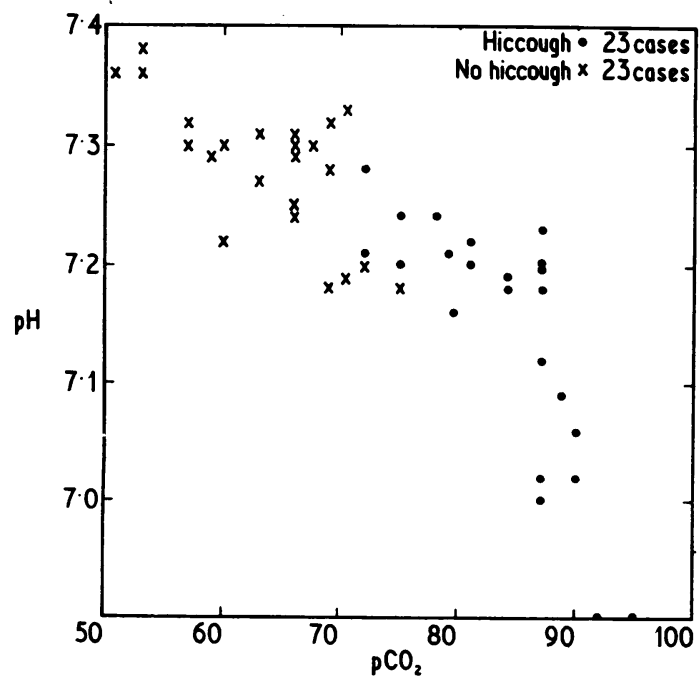

FIG.5.-The relation of $\mathrm{pCO}_{2}$ and $p \mathrm{H}$ to hiccough during abdominal surgery. The figures are statistically significant.

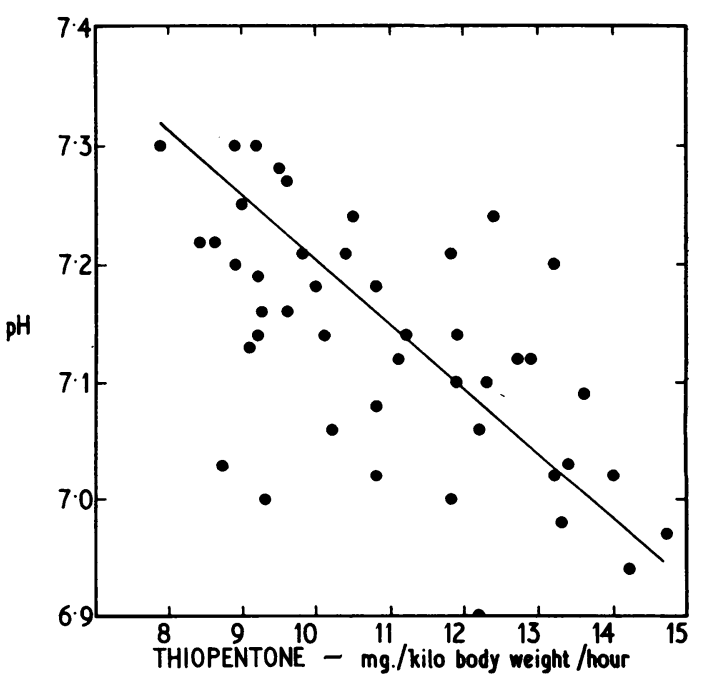

FIG. 6.-Relationship of $p \mathrm{H}$ to dosage of thiopentone in 45 patients breathing spontaneously during abdominal operations. There is a significant correlation. 
post-operatively and all showed signs of shock. In long operations the rise in blood pressure was only present for part of the time, then there was a sudden fall and a general circulatory collapse. This was most noticable in the 12 patients operated upon in the Trendelenburg position, and two of these, who developed a severe acidosis with a $p H$ of 6.9 and a $\mathrm{pCO}_{2}$ of 92 , needed extensive resuscitation post-operatively. On several occasions, notably during oesophagectomy, the patient's condition was improved by stopping the operative procedure temporarily and ventilating maximally for a few minutes (Fig. 4).

As well as being a contributory factor to shock, a respiratory acidosis was related to the incidence of hiccough during surgery. This complication occurred in 23 out of 46 patients undergoing upper abdominal surgery and in every one was preceded by a rise in $\mathrm{pCO}_{2}$ of 24 to $27 \mathrm{~mm}$. and a fall in $p \mathrm{H}$ of 0.12 to 0.5 . It never occurred under alkalotic conditions (Fig. 5). "Vigorous" overventilation reduced the acidosis, and of the 23 cases the hiccough was cured in six, relieved temporarily in seven, and unchanged in 10 . The association of hiccough with a respiratory acidosis is of interest because most of the accepted modes of treatment are bronchodilator in character, so aiding ventilation and the elimination of carbon dioxide (Lucas, 1952). Overventilation becomes difficult once hiccough has started, because the condition itself produces a bronchoconstriction which hampers ventilation. This may account for the fact that many bronchodilator drugs are of value prophylactically and yet their action in the treatment of the complication is variable.

A further observation made during this investigation was that the dosage of thiopentone was increased under acidotic conditions (Fig. 6). The reason was not established, but Dundee (1952) has reported similar findings. Possibly the rate of breakdown of the barbiturates varies with the $p \mathrm{H}$ changes in the blood. Alternatively, changes in acid base balance alter the susceptibility of the brain to narcotics.

\section{SUMMARY}

The acidosis which occurs during modern anaesthesia is respiratory in origin because of the depressant effect of the anaesthetic agents on the respiratory centre and the paralysing effect of relaxants on the muscles of respiration.

The unconscious patient is incapable of ventilating himself efficiently, and positive pressure artificial respiration has to be performed to maintain a normal acid base balance. This can be done satisfactorily in the supine position, but the minute volume necessary is greater than that of normal spontaneous respiration, due to the fact that positive pressure artificial ventilation is unphysiological and therefore relatively inefficient. In the lateral or Trendelenburg positions, or when intrathoracic operations are carried out, ordinary positive pressure - ventilation cannot eliminate carbon dioxide effectively and a severe acidosis can develop unless vigorous overventilation is performed throughout the operation. If this is not practicable because of the nature of the surgical intervention, pauses should be made from time to time to allow maximum ventilation.

A respiratory acidosis during surgery is harmful because it predisposes to shock and troublesome reflexes are more likely to occur. Larger amounts of anaesthetic agents are needed and postoperative recovery is delayed.

We are grateful to Dr. C. E. Dent, reader in medicine, University College Hospital Medical School, for the design of the special sampling syringe, and to Miss J. M. McAlister, assistant physicist, University College Hospital, who did the statistical analysis. We also thank the surgeons and anaesthetists of University College Hospital for allowing us to make observations on their patients.

\section{REFERENCES}

Ankeney, J. L., Hubay, C. A., Hackett, P. R., and Hingson, R. A. (1954). Surg. Gynec. Obstet., 98, 600.

Beecher, H. K., and Murphy, A. J. (1950). J. thorac. Surg., 19, 50. Best, C. H., and Taylor, N. B. (1955). The Physiological Basis of Medical Practice, 6th ed., p. 134. Baillière, Tindall and Cox, London.

Comroe, J. H., Forster, R. E., Dubois, A. B., Briscoe, W. A., and Carlsen, C. (1955). The Lung. Clinical Physiology and Pulmonary Function Tests. 1st ed., p. 171. Year Book Publishers, Chicago.

Cournand, A., Motley, H. L., Werko, L., and Richards, D. W. (1948). Amer. J. Physiol., 152, 162.

Dundee, J. W. (1952). Brit. med. J., 2, 893.

Lucas, B. G. B. (1952). Anaesthesia, 7, 88.

Peters, J. F., and Van Slyke, D. D. (1932). Quantitative Clinical Chemistry; Vol. 2: Methods. 1st ed., p. 298. Baillière Tindall and Cox, London.

Robson, J. G., and Pask, E. A. (1954). Brit. J. Anaesth., 26, 333. I

Scholander, P. F., and Roughton, F. J. W. (1943). J. biol. Chem. $148,573$.

Taylor, F. H., and Roos, A. (1950). J. thorac. Surg., 20, 289.

Van Slyke, D. D., Austin, J. H., and Cullen, G. E. (1922). J. biol. Chem., 53, 277. 